\title{
La persona en el grado civil. Crítica a la realidad del proceso de adopción y no adopción de adolescentes*
}

\author{
Janeth Carolina Barrera Sandovak* \\ Manuel Mauricio Moreno Villamizar***
}

Recepción: 30 de Agosto de 2017

Aprobación: 9 de octubre de 2017

\section{RESUMEN}

El presente artículo contiene los resultados alcanzados dentro del proyecto de investigación cuyo objetivo fue indagar el proceso de adopción y no adopción de los adolescentes en el Instituto Colombiano de Bienestar Familiar (ICBF) en el departamento del Meta. Uno de los fines del ICBF es dirigir y entregar en adopción a los titulares de derechos vulnerados, buscar una familia para lograr restablecer derechos de los menores y brindarles estabilidad familiar a través de la figura de la adopción, en una relación paternofilial entre personas que no la tienen por naturaleza. Se analiza de igual forma el seguimiento y garantías que brinda el Estado a través del ICBF frente a los adolescentes adoptados y no adoptados y todos los factores que abordan la problemática de estos adolescentes en el entorno social y cultural.

Palabras clave: adopción, adolescente, impúber, púber, hogares sustitutos y prevención.

* El artículo es producto del proyecto de investigación "La persona en el grado civil. Crítica a la realidad del proceso de adopción y no adopción de adolescentes”, gestionado en el marco del programa de pregrado de la Universidad Santo Tomás, Sede Villavicencio - Colombia. DOI: http://dx.doi.org/10.15332/s1909-0528.2018.0001.04

** Estudiante del Programa de Derecho, VIII semestre. Integrante del semillero en Filosofía y Teoría del Derecho de la Universidad Santo Tomás, Sede Villavicencio - Colombia. janeth.barrera@usantotomas.edu.co

*** Abogado y licenciado en Ciencias Religiosas y Éticas. Especialista de la Administración de la Informática Educativa de la Universidad de Santander, Bucaramanga - Colombia. Especialista de Derecho Laboral y Seguridad Social de la Universidad Libre, Bogotá - Colombia. Magíster en Gestión de la Tecnología Educativa. Docente de tiempo completo Universidad Santo Tomás, Sede Villavicencio - Colombia. morenovillamizar@hotmail.com 


\begin{abstract}
This article contains the results achieved within the research project whose objective was to investigate the process of adoption and non-adoption of adolescents in the Colombian Family Welfare Institute (ICBF), in the department of Meta. One of the aims of the ICBF is to lead and to deliver in adoption to the holders of rights violated; to find a family to achieve reestablishment of the rights of minors and provide family stability through a figure adoption, in a parent-child relationship between people who do not have it by nature. It also analyzes the monitoring and guarantees provided by the State through the ICBF against adopted and non-adopted adolescents and all the factors that approach the problems of these teenagers in the social and cultural environment.
\end{abstract}

Keywords: adoption, adolescent, prepubescent, pubescent, foster homes and prevention.

\title{
INTRODUCCIÓN
}

El Instituto Colombiano de Bienestar Familiar (ICBF) es una entidad creada bajo el gobierno de Carlos Lleras Restrepo, el 30 de diciembre de 1968 con la Ley 75 de 1968, por medio de la cual se buscaba regular las situaciones de discriminación, maltrato a la población infantil y hacer un frente a la irresponsabilidad familiar, la deficiencia nutricional, la pérdida de valores y la nińez abandonada, entre otras problemáticas. Esta entidad está adscrita al Ministerio de Salud y Protección Social, y se encuentra ubicada en todas las capitales de los departamentos del país. Todo esto para mejorar la calidad de vida de muchos niños, adolescentes y familias a través de asistencia social y comunitaria.

Esta entidad está encargada del restablecimiento de derechos de los niños y adolescentes, con el fin de brindar bienestar y seguridad a todos los menores de edad. Uno de los objetivos del ICBF es dirigir y entregar en adopción a los titulares de derechos vulnerados, buscar una familia a través de la declaratoria de adopción, la cual inicia luego de que ICBF tiene conocimiento de la vulneración que sufre un menor de edad. Cuando un nińo o adolescente se queda sin familia, es abandonado por esta o ha sido objeto de maltrato o alguna clase de violencia, se abre entonces el proceso de restablecimiento de derechos a través del ICBF como la institución encargada de 
restablecer derechos de los menores o como la entidad con la facultad de autorizar a diferentes fundaciones para que realice el proceso de adopción, actualmente existen ocho fundaciones autorizadas por el ICBF como Fundación los Pisingos (Bogotá, Colombia), Fundación casita de Nicolás (Medellín, Colombia), entre otras (Instituto Colombiano de Bienestar Familiar, s.f.).

Por lo anterior, se busca brindarles una estabilidad familiar a través de la adopción, pero mientras llega ese proceso los nińos y adolescentes que no se encuentran en ambientes familiares y están bajo la custodia del ICBF se ubican en hogares sustitutos para que les ofrezcan la posibilidad de establecer vínculos, dependiendo de la edad en que se encuentran, con el fin de ayudarles a recuperar el vacío afectivo, vigilado por la entidad, para que tengan un contexto de familia sustituto transitorio mientras se formaliza la figura del grado civil a través de la adopción y de esta forma logre identificarse e integrarse a una familia, permitiendo fortalecer vínculos afectivos para garantizar su desarrollo armónico e integral.

Los hogares sustitutos son una modalidad de atención que corresponde a una medida de restablecimiento de derechos definida en el artículo 59 del Código de la Infancia y la Adolescencia como "la ubicación del nińo, la nińa o el adolescente en una familia que se compromete a brindarle el cuidado y atención necesarios en sustitución de la familia de origen". Es una alternativa de vida en un ambiente familiar, donde se retoma el proyecto de vida de cada nińo o adolescente para acompañarlo y fortalecerlo, buscando la formación holística de personas, autónomas y seguras de sí misma con capacidad de enfrentarse a los retos personales, familiares, sociales y laborales.

La investigación se centra de forma específica en la adopción de los adolescentes y la problemática que los rodea en torno a los hogares sustitutos y derivados de la adolescencia. La adolescencia es una etapa de todos los seres humanos dentro del proceso evolutivo del hombre, en donde se experimentan diferentes cambios físicos, psicológicos, emocionales y sociales. A partir de estos cambios, el adolescente comienza a construir pensamiento, carácter, decisiones e identidad, pero como punto de partida está la familia, tal como expresa el artículo quinto de la Constitución Política de Colombia que prescribe: "El Estado reconoce, sin discriminación alguna, la primacía de los derechos inalienables de la persona y ampara a la familia como institución básica de la sociedad" (Colombia, 1991). 
La base viene de la familia, pero ¿qué ocurre cuando se presenta la ausencia de esta base? ¿Qué apoyo social tienen estos adolescentes? Es muy difícil establecer una tendencia general para todas las situaciones de ausencia, cada persona responde diferente ante las dificultades o preguntas de la vida. Pero, si se puede establecer que en muchas ocasiones estos adolescentes no corren con suerte y terminan siendo una gran preocupación social y estatal.

Por consiguiente el Estado colombiano, como Estado social de derecho, debe responder a través del ICBF las contingencias que se presentan con una población que no crece en un ambiente familiar y se debe hacer cargo por medio de los hogares sustitutos, para formar ciudadanos en igualdad de condiciones. Lo anterior entre otras razones porque "la política social ha encontrado nuevos referentes dentro de la globalización, en la cual juega un papel central el esquema de necesidades humanas" (Páez et al., 2017); y porque el orden jurídico-constitucional de 1991 construido sobre el paradigma del Estado social de derecho presupone que los órganos estatales deben resolver problemas sociales a través de la norma jurídica, en aras de lograr que el derecho pueda solucionar el orden social injusto (Camargo, 2016).

¿Quiénes son los adolescentes? De acuerdo al Código de Infancia y Adolescencia, Ley 1098 de 2006, establece en su artículo $3^{\circ}$ :

Sujetos titulares de derechos. Para todos los efectos de esta ley son sujetos titulares de derechos todas las personas menores de 18 años. Sin perjuicio de lo establecido en el artículo 34 del Código Civil Colombiano, se entiende por niño o niña las personas entre los 0 y los 12 años, y por adolescente las personas entre 12 y 18 ańos de edad.

Ahora bien, el artículo 34 del Código Civil Colombiano fue modificado parcialmente por la Ley 1306 de 2009, al afirmar que

Llámase infante o niño, todo el que no ha cumplido siete años; impúber, el que no ha cumplido catorce; adulto, el que ha dejado de ser impúber; mayor de edad, o simplemente mayor, el que ha cumplido dieciocho años, y menor de edad, o simplemente menor, el que no ha llegado a cumplirlos... 


\section{Problema de inVestigación}

Es necesario enmarcar algunas de las principales características de una política pública orientada al ejercicio efectivo de los derechos humanos y derechos fundamentales. Es decir, en procura de la materialización de la dignidad humana (Cortez, 2016). En concordancia con lo dispuesto anteriormente, coincidimos con el profesor Parejo, para quien la actualidad demanda la revitalización del valor de la dignidad del hombre (Parejo, 2016); y en este sentido, dada la importancia de la Institución de la Familia en el Estado colombiano, esta ha sido objeto de protección y merecedora de instrumentos de garantización por marcos normativos nacionales internacionales (Morales, 2017).

Desde la perspectiva jurídica referenciada, hay un grupo de menores de edad bajo la custodia del ICBF que se encuentran en condición de adoptabilidad, pero tienen una serie de características especiales que los convierten en menores de edad de difícil adopción, tales como los niños mayores de ocho años, los que se encuentran en Bienestar Familiar en grupos de hermanos y aquellos que tienen alguna discapacidad o enfermedad. Además, la situación que viven los adolescentes en los hogares sustitutos posiblemente no les brinda las garantías mínimas de un ambiente familiar que busca la formación integral de la persona y su preparación al contexto personal, familiar, social y laboral.

Surge entonces una problemática en el ICBF, que describe una serie de fenómenos jurídicos frente al proceso de adopción y no adopción de los adolescentes que se encuentran en esa institución del Estado, como la ausencia real de un ambiente familiar, la necesidad de estos adolescentes por tener una familia, un mayor apoyo del Estado en el campo cultural, social y laboral, como también una toma de conciencia estatal por parte de la población colombiana en el proceso de adoptabilidad de estos menores de edad.

Frente a lo anterior, surgen los siguientes interrogantes: ¿Cuál es el promedio anual de adopción de adolescentes entre los años 2012 al 2014 en el departamento del Meta? ¿Cuál es el seguimiento que realiza el ICBF de los adolescentes adoptados? ¿Qué herramientas brinda el ICBF para promover la adopción de los adolescentes? ¿Cuáles son las características y condiciones especiales que dificultan el proceso de 
adoptabilidad en los adolescentes? ¿Qué ocurre con aquellos adolescentes que no son adoptados? ¿Qué garantías brinda el Estado a través del ICBF frente a los adolescentes que no son adoptados? ¿Cuáles son las problemáticas que asumen los adolescentes en el entorno social?

\section{LA INVESTIGACIÓN EN EL ENTORNO Y SU JUSTIFICACIÓN}

Desde el punto de vista psicológico, dentro del proceso evolutivo del hombre, el adolescente es un constructo social (Papalia, Wendkos y Duskin, 2009), es decir, fruto de una construcción social. Se define también como el proceso de transición del desarrollo entre la infancia y la adultez que implica cambios físicos, cognitivos y psicosociales importantes (Almonte y Montt, 2012).

Los adolescentes que están bajo la custodia del ICBF y en proceso de adopción, o mejor, que se encuentran listos para ser parte de un proceso de adopción, para recibir una familia nueva, viven una situación compleja ante la ausencia de los padres biológicos que no han estado cerca e involucrados en sus vidas, por ende, esa ausencia incide en el comportamiento de los adolescentes ya que requieren de unos modelos y estilos de vida a seguir, afectando el proyecto personal, familiar, social y profesional de los adolescentes, que en la mayoría de los casos crecen con dificultades afectivas y psicológicas, propias de la etapa de su desarrollo que se ahonda ante la carencia o ausencia de un real ambiente familiar.

Así que el manejo actual de esta situación es que dichas consecuencias afectivas originadas por la ausencia de los padres se trate de suplir con ayudas estatales, proyectos como "hogares sustitutos".

Pero en realidad, no se llenan las expectativas de una familia y en algunos casos se reflejan en comportamientos negativos o asociales sin olvidar el ambiente social donde crecen y la influencia de los padres o compañeros, quienes inciden en su comportamiento.

En este orden de ideas, se ha determinado a través de una serie de investigaciones cómo los comportamientos delincuenciales y antisociales de los adolescentes surgen 
en gran parte por la ausencia real de una familia, de acuerdo con los estudios de la conducta social del hombre (Rhee y Waldman, 2002; Tackett et al., 2005).

Los padres modelan la conducta social o antisocial mediante sus respuestas a las necesidades emocionales básicas de los niños (Krevans y Gibbs, 1996). Cuando se comportan de manera inapropiada o violenta es posible que busquen atención o llenar vacíos afectivos que brotan más en los adolescentes que se encuentran bajo la custodia del ICBF y están en proceso de adoptabilidad.

Los adolescentes se encuentran en una edad donde el proceso de adopción es nulo, es decir, para un adolescente la oportunidad de ser adoptado y tener una nueva familia no existe, porque las familias o padres adoptantes prefieren infantes o nińos menores de siete años.

Lo anterior se funda en la respuesta que da el ICBF frente al requerimiento que se les hace a través de un derecho de petición, donde se les pregunta cuál es el porcentaje o número de adolescentes entre la edad de los trece a los diecisiete ańos que entraron a un proceso de adopción en los últimos años. A lo cual aseguraron que ninguna familia o padres adoptantes en el departamento del Meta presentan interés en esta edad o etapa del proceso evolutivo del hombre.

Esta situación ahonda entonces el conflicto personal y social de los púberes, quienes saben muy bien que la oportunidad de selección o escogencia en el proceso de adopción es baja, o mejor, nula.

Por lo anterior, la crítica al proceso de adopción no solo se enfoca a malos procedimientos o proyectos estatales para cuidar al adolescente y proveerle un futuro sano y seguro. La crítica va mucho más allá, se enfoca en el joven, en las personas o familias adoptantes y la esperanza a que se considere adoptar menores de las edades mencionadas.

En concordancia con lo dispuesto anteriormente, mientras en Colombia se siga avanzando por el camino del desconocimiento de los derechos, esto es, mientras no se satisfagan los derechos constitucionales y mientras se sigan generando políticas públicas que tiendan a profundizar estas estructuras de inequidades e injusticias, 
mayor será la responsabilidad como profesionales del derecho en analizar estas problemáticas (Saidiza y Carvajal, 2016).

\section{Metodología}

La presente investigación es de carácter cualitativo porque se trata de comprender los motivos que generan las relaciones humanas en el contexto social, orientadas en la percepción jurídica de la realidad.

Se estudia y analiza la realidad de la adopción de los adolescentes y la problemática que los rodea en torno a los hogares sustitutos y derivados de la pubertad, analizando el proceso de adoptabilidad de los menores de edad.

Determinando que la investigación es cualitativa, se especifica el carácter de investigación, porque el objetivo es interpretar la información obtenida a través del Instituto Colombiano de Bienestar Familiar y sistematizar las experiencias de los hogares sustitutos frente al estudio de una población determinada como son los adolescentes.

La población de análisis del presente artículo de reflexión fue en primer lugar la información que brindó el ICBF y Policía Nacional de la Infancia y Adolescencia como también la encuesta realizada a hogares sustitutos en el municipio de Villavicencio, departamento del Meta.

Se tomó como muestra doce hogares sustitutos en el mes de octubre de 2015, ubicados en las diferentes comunas del municipio.

Como procedimiento metodológico en la investigación cualitativa, se realizó una encuesta, utilizando un formulario impreso, destinado a obtener repuestas sobre el problema en estudio, con preguntas semicerradas (semiestructuradas), que permite determinar y desvelar la temática en estudio para lograr una eficiente y pronta codificación de los resultados y evitar salirse de los parámetros de estudio. 


\section{Resultados}

La información suministrada por la Dirección General del ICBF del Meta y la Policía Nacional de la Infancia y Adolescencia Regional Meta, así como también la encuesta realizada a los hogares sustitutos en el municipio de Villavicencio, fue significativa para delimitar y concretar la investigación. En primer lugar, la Dirección General del ICBF del Meta expresa que entre el periodo de 2012 al 2015 no se ha iniciado ni realizado ninguna clase de adopción de adolescentes. Que los adolescentes tienen un continuo acompańamiento a través de un grupo interdisciplinario de profesionales que los ayudan a superar las contingencias y situaciones propias de su edad.

El Instituto Colombiano de Bienestar Familiar (ICBF), dando respuesta a los requerimientos solicitados en el derecho de petición sobre el proceso de adoptabilidad e inconvenientes frente a este con número de radicado S-2015-229255-5000, informa la dificultad en el proceso de adopción de los púberes que se encuentran bajo la custodia del ICBF dentro de los ańos comprendidos entre 2012 al 2015, en razón de sus características especiales, es decir, en razón de su edad.

La situación de los niños y niñas adolescentes que pueden ser adoptados tienen sus derechos inobservados, amenazados o vulnerados, lo que implica que se inicie un proceso administrativo de restablecimiento de derechos, por las diversas problemáticas como de maltrato y violencia familiar, consumo de sustancias psicoactivas (SPA), reclutamiento forzado, víctimas de abuso que inciden notablemente en el desarrollo de los adolescentes producto del abandono en la mayoría de los casos de sus padres o porque sin ser abandonados no son sus padres o sin tener la custodia de los jóvenes no garantizan la defensa de sus derechos, impidiendo un desarrollo integral en su personalidad, derechos que se han venido restableciendo una vez que los adolescentes ingresan bajo medida de restablecimiento de derechos en el ICBF.

Por tal razón, la adopción es principalmente una medida de protección integral al púber a través de la cual bajo la vigilancia del Estado se establece de manera irrevocable la relación paternofilial entre personas que no la tienen por naturaleza.

El ICBF expresa que ellos se rigen por el lineamiento de hogares sustitutos donde el proceso de selección de estos hogares se rige por que estos brinden y ofrezcan 
las mejores condiciones socioafectivas y culturales para el desarrollo armónico de los púberes que cuentan con alto nivel de compromiso con el cuidado y restablecimiento de derechos. Es así que el proceso debe ser adelantado por el equipo técnico interdisciplinario por medio de un proceso abierto para recibir las candidaturas para constituirse como hogares sustitutos.

Sobre la formación académica, técnica y laboral de los adolescentes y acompañamiento psicológico que reciben en los hogares sustitutos, informa el ICBF que inician proceso desde los nueve años con proyectos de vida hasta los dieciocho años o más si se encuentran en proceso educativo con buen rendimiento, carreras técnicas, tecnológicas y profesionales.

Manifiesta el ICBF que los mayores de edad que terminan sus estudios universitarios o técnicos previa preparación egresan del programa. Ese es el acompańamiento que les brinda a los adolescentes y jóvenes que hacen parte del programa de hogares sustitutos y que no lograron hacer parte del proceso de adoptabilidad.

Se aclara que el ICBF a través de los hogares sustitutos busca el sano desarrollo integral de los niños, niñas, y adolescentes con el fin de brindarles protección para el sujeto en todas las etapas del ciclo vital. En este sentido, la atención en medio familiar debe privilegiarse respecto de la atención en medio institucional, ya que ofrece a los niños, niñas y adolescentes un contexto de familia sea el propio o uno sustituto transitorio, permitiendo fortalecer vínculos afectivos para garantizar su desarrollo armónico e integral.

Los Hogares Sustitutos son una modalidad de atención que corresponde a una medida de restablecimiento de derechos definida en el artículo 59 del Código de la Infancia y la Adolescencia como "la ubicación del niño, la niña o el adolescente en una familia que se compromete a brindarle el cuidado y atención necesarios en sustitución de la familia de origen”.

Es una alternativa de vida en familia, en donde se retoma el proyecto de vida de cada niño o niña para reconstruirlo y fortalecerlo, buscando a futuro la formación de un ser humano autónomo y seguro y con capacidad de enfrentarse a los retos personales, familiares, sociales y laborales. 
Ahora bien, el comunicado de la Policía Nacional de la Infancia y Adolescencia Regional Meta expresa que a través del aplicativo Siedco, "Sistema de Información Estadístico Delincuencial, Contravencional y Operativo de la Policía Nacional”, donde se registran las actividades preventivas, disuasivas, de control, contravenciones y delitos conocidos por el personal policial aparece según la información proporcionadas en las tablas 1 y 2 suministradas por la Policía Nacional de la Infancia y la Adolescencia, Regional Meta (Demet, 4 de junio de 2015).

Tabla 1. Cifras de menores víctimas durante los periodos 2012 a 2015 Demet

\begin{tabular}{|l|l|c|c|c|c|}
\hline \multicolumn{2}{|c|}{ Víctimas de delitos } & $\mathbf{2 0 1 2}$ & $\mathbf{2 0 1 3}$ & $\mathbf{2 0 1 4}$ & $\mathbf{2 0 1 5}$ \\
\hline \multirow{5}{*}{} & Edad de 12 a 17 años & Total & Total & Total & Total \\
\cline { 2 - 6 } & Homicidio & 10 & 12 & 13 & 1 \\
\cline { 2 - 6 } & Homicidio culposo en a. de tránsito & 3 & 1 & 1 & \\
\cline { 2 - 6 } & Lesiones personales & 39 & 48 & 35 & 6 \\
\cline { 2 - 6 } & Lesiones personales en a. de tránsito & 17 & 22 & 10 & 1 \\
\cline { 2 - 6 } & Delitos sexuales & 58 & 41 & 36 & 23 \\
\cline { 2 - 6 } & Injuria y calumnia & 3 & & 5 & \\
\cline { 2 - 6 } & Injuria vía de hecho & 4 & 12 & 15 & 6 \\
\cline { 2 - 6 } & Violencia intrafamiliar & & 2 & 2 & \\
\cline { 2 - 6 } & Ej. arbitrario custodia & 24 & 23 & 32 & 10 \\
\cline { 2 - 6 } & Inasistencia & 195 & 183 & 152 & 50 \\
\cline { 2 - 6 } & Otros & & & & \\
\hline \multirow{4}{*}{ Total } & & 37 & 22 & 2 & 1 \\
\hline
\end{tabular}

Nota: cifras extraídas por la Policía Nacional de la Infancia y la Adolescencia, Regional Meta (Demet): 4 de junio de 2015 . 
Tabla 2. Cifras de menores victimarios durante los periodos 2012 a 2015 Demet

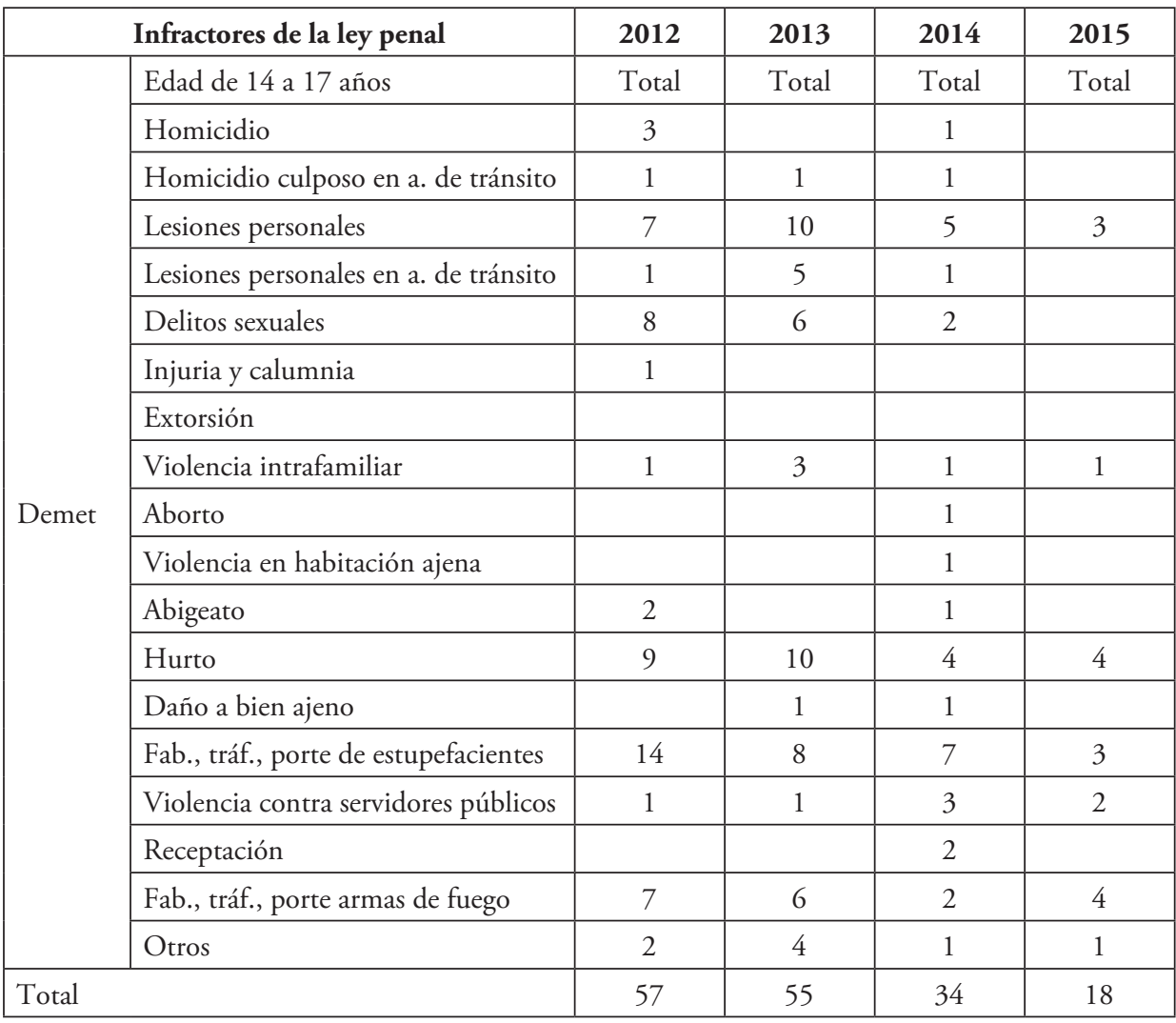

Nota: cifras suministradas por la Policía Nacional de la Infancia y la Adolescencia, Regional Meta (Demet): 4 de junio de 2015 .

Es de anotar que todos los casos que aparecen en la tabla 1 y en la tabla 2 son entregados al fiscal de turno y remitidos de igual forma a la autoridad competente para el restablecimiento de derechos de nińos, nińas y adolescentes correspondientes a cada caso, como son: delitos sexuales remitidos al Caivas, "Centro de Atención Víctimas Abuso Sexual”, y/o Medicina Legal; problemas de conducta, maltrato infantil, violencia intrafamiliar, custodias, inasistencia alimentaria, los cuales son remitidos 
a comisarias de Familia y al ICBF; en caso de homicidios y lesiones personales son remitidos a centros de salud y similares, así como a Medicina Legal.

Se aclara que en el departamento del Meta no se cuenta con internados para adolescentes infractores de la ley penal y el único que se encuentra en el departamento del Meta es la Corporación Encuentro Aldea Agua Clara, en la ciudad de Villavicencio, ubicado en la jurisdicción de la Policía Metropolitana de Villavicencio.

La Policía Nacional de la Infancia y Adolescencia Regional Meta, en atención a los postulados de la Ley 1098 de 2006, especialmente lo relacionado con los artículos 88,89 y 145 , fijó lineamientos específicos donde se incorpora estrategias para el año 2015 en las tres líneas de acción (prevención, vigilancia y control e investigación criminal) tendientes a mitigar las situaciones de vulnerabilidad y riesgo a la que se ven expuestos los niños, niñas y adolescentes de Colombia, basados en diagnósticos y análisis estadísticos.

Estas estrategias buscan disminuir en un porcentaje significativo la participación de niños, niñas y adolescentes en los delitos como víctimas o victimarios y contrarrestar la situación de vulnerabilidad y riesgo en la cual se ven expuestos los menores, según se muestra a continuación.

\section{Prevención}

Componente mediante el cual se quiere evidenciar y atender corresponsablemente las condiciones de vulnerabilidad y riesgo a las cuales se ven expuestos los niños, niñas y adolescentes, comprometiendo a la Policía Nacional y el colectivo social. Desde el programa "Abre tus Ojos" se abordan las principales vulneraciones de derechos que afectan los niños, niñas y adolescentes, a través de estrategias de enseñanza y aprendizaje que contribuyen a mitigar o reducir los riesgos que afectan esta población.

Cuenta con 36 temáticas entre las cuales se encuentran la prevención del consumo de sustancias psicoactivas, tabaco y bebidas embriagantes, prevención pandillas juveniles, prevención del suicidio, prevención del maltrato infantil, prevención de la violencia intrafamiliar, prevención violencia y abuso sexual. 


\section{VIGILANCIA Y CONTROL}

Es la manera como, a través de planes especiales dirigidos a puntos críticos, se busca disuadir y neutralizar los factores potencialmente nocivos para los niños, niñas y adolescentes, interviniendo lugares públicos, establecimientos abiertos al público y sitios de gran afluencia de personas que generen posibles riesgos para la niñez y la adolescencia colombiana.

Tales planes son: explotación laboral infantil; control de lugares donde se ejerza la explotación sexual (como profesión), donde se realicen espectáculos no aptos para niños, niñas y adolescentes; control en establecimientos abiertos al público; control en establecimientos educativos; control lugares de diversión destinados al consumo de bebidas alcohólicas y cigarrillos.

\section{INVESTIGACIÓN CRIMINAL}

Este componente se constituye en el último nivel que tiene la especialidad para contribuir a garantizar la protección integral de los niños, niñas y adolescentes, se ejecuta a través de acciones investigativas, tendientes a contrarrestar las redes delictivas que someten a los adolescentes a la condición de victimarios y a los niños, niñas y adolescentes en condición de víctimas de conductas punibles.

Ahora bien, de acuerdo con la encuesta realizada en octubre de 2015 a los hogares sustitutos en el municipio de Villavicencio, se detalla la preferencia de los padres adoptantes por los menores de ocho años en el proceso de adopción en un 100\%.

Se describe como problemática de los adolescentes en los hogares sustitutos los fenómenos de drogadicción en un $8 \%$, alcoholismo $0 \%$, pandillas $27 \%$, violencia y agresividad $17 \%$, comportamientos de carácter sexual $8 \%$, comportamientos suicidas $8 \%$, comportamientos delictivos como hurto $0 \%$, todas las anteriores $27 \%$ y problemas psicológicos en los jóvenes por motivo de la aceptación y adaptación en un nuevo hogar $7 \%$. 
Ahora bien, referente a la formación que brinda el Estado a través del ICBF se especifica en un $96,5 \%$ que reciben formación académica, técnica y profesional, mientras que el 3,5\% rechazan las ventajas y beneficios debido a que los adolescentes desertan en el proceso de formación.

Sobre los correctivos que se emplean con los adolescentes infractores por parte de los hogares sustitutos se estableció con asesoría psicológica un $8 \%$, con sanciones de actividades como por ejemplo del celular, televisión y salida a la calle un 34\%, con la entrega al ICBF para su reubicación un 18\%, otra gran parte considera todas las anteriores con un 34\% y compartiendo que todos los anteriores correctivos son válidos no son aplicados a todos los casos, depende del acto de indisciplina que se haya cometido equivalente al $6 \%$.

En aras de conocer la preparación y disposición de las madres u hogares sustitutos para con el menor afectado por diversas situaciones originadas en su hogar primario, se preguntó sobre el proceso de selección de los hogares sustitutos.

Los hogares sustitutos, dado su compromiso con el Estado y en primera medida con el menor, deben ser espacios capacitados, amorosos y con personas dispuestas a brindar al menor o los menores adolescentes que allí lleguen una estabilidad emocional y una vida alejada del maltrato que originó la separación con su familia primaria.

De igual forma no pueden separar su objetivo del artículo 59 de la Ley 1098 del 2016, "Código de Infancia y Adolescencia", el cual define el componente, la razón de ser o propósito de un hogar sustituto.

Ahora bien, tendemos a confundir el hogar de paso con los hogares sustitutos y es que estos deben tener la misma capacidad de respeto, responsabilidad y compromiso con el menor. El concepto 22174 del 30 abril de 2008 nos aclaró que la diferencia radica en el tiempo durante el cual estos hogares brindan voluntariamente su ayuda a los menores y por supuesto cada uno contiene unos lineamientos técnicosadministrativos diferentes consagrados en las resoluciones número 2365 del 24 de septiembre de 2007 y 912 del 12 de mayo de 2007. 
El artículo 57 de la Ley 1098 de 2006 menciona que la ubicación en un hogar de paso, como es una medida provisional para garantizar los derechos especialísimos que tienen los menores, poseen un término no superior a ocho días hábiles; durante dichos días la autoridad competente tendrá que resolver o decretar otra medida de protección para el menor.

Para los hogares sustitutos, el artículo 59 anteriormente mencionado da un término no superior a seis meses, los cuales pueden ser prorrogables, dependiendo de la situación del caso y los derechos del menor según sentencia de la Corte Constitucional T-849 de 1999, la cual dicta que "la ausencia de la familia tiene que ser suplida por el Estado. De modo que, si es imposible el cumplimiento de las obligaciones radicadas en cabeza de la familia y a favor del niño, el Estado está llamado a cumplirlas”.

Los menores de edad deben ser y son la prioridad para nuestra nación, tanto el Estado colombiano como la sociedad debe tener claridad de lo especial y primordial que son los derechos de los menores de edad en Colombia.

Un menor de edad debe estar plenamente tranquilo en su persona y tener la confianza de poder desarrollarse en un entorno seguro y apropiado, una sociedad y un Estado que le garantizara las herramientas necesarias para su desarrollo como persona.

Según, el "Lineamiento técnico de modalidades para la atención de niños, niñas y adolescentes, con derechos inobservados, amenazados o vulnerados" (Instituto Colombiano de Bienestar Familiar, 2017), versión 4 el cual fue aprobado por las siguientes resoluciones de la misma entidad:

- Aprobado mediante Resolución No. 1520 de febrero 23 de 2016

- Modificado mediante Resolución No. 5863 de junio 22 de 2016

- Modificado mediante Resolución No. 7960 de agosto 10 de 2016

- Modificado mediante Resolución No. 13366 de diciembre 23 de 2016

- Modificado mediante Resolución No. 244 de enero 20 de 2017

- Modificado mediante Resolución No. 1261 de marzo 2 de 2017 
La modalidad hogar sustituto, de acuerdo con el "Lineamiento técnico del modelo de atención de niños, niñas y adolescentes con derechos amenazados, inobservados o vulnerados", comprende:

1. Hogar sustituto vulneración.

2. Hogar sustituto discapacidad o enfermedad de cuidado especial.

3. Hogar sustituto tutor para niños, niñas y adolescentes desvinculados de grupos armados, organizados al margen de la Ley.

Según el informe del ICBF sobre los lineamientos de los hogares sustitutos, estos deben tener un control y unas reglas claras, para recibir a los menores en su hogar. Por supuesto, esto varía según la situación del menor, se estima que en promedio un hogar sustituto puede recibir entre uno a tres menores.

El representante del hogar sustituto ante el ICBF será la madre sustituta o tutora, o de igual forma también será el padre sustituto o tutor, lo anterior depende de quien haya surtido el proceso y obtenga la respectiva aprobación a través de la resolución de apertura que se inició con el coordinador del Centro Zonal.

También se le exige a cada hogar sustituto que debe llevar durante todo el tiempo que se encuentre vinculado con la entidad pública una carpeta de seguimiento, la cual contendrá los respectivos permisos, documentos e información de los menores que ingresen al hogar.

El ICBF aportará los recursos necesarios para garantizar la efectividad del proceso de restablecimiento de derechos de los niños, niñas y adolescentes en los hogares sustitutos. Cada mes el padre o madre sustituto(a) recibirá lo correspondiente a cuota de sostenimiento, dotación personal y escolar del menor, y gastos de emergencia.

Se debe aclarar que la relación que se crea entre las personas madres o padres sustitutos y el ICBF, en razón del servicio de hogares sustitutos, bajo ninguna circunstancia será una relación laboral. 
Finalmente es una obligación de los servidores públicos del ICBF llevar una vigilancia constante de los diferentes hogares sustitutos, se programa una evaluación semestralmente para observar el nivel de satisfacción de los menores con el programa. Y de igual forma se evalúa el nivel de satisfacción que tienen las madres o padres sustitutos con el apoyo del ICBF.

\section{Conclusión}

El Estado colombiano como Estado social de derecho, teniendo como marco la Convención de los Derechos del Niño y la Constitución Política, debe comprometerse con la promoción y garantía de los derechos de los niños y adolescentes a través del ICBF con la articulación de estrategias que promuevan los derechos de los niños y adolescentes e involucre una participación responsable de la familia y la sociedad con la selección de hogares sustitutos que brinden un ambiente familiar, con los hogares de paso, centros de emergencia, casa/hogar, internado, entre otros.

Uno de los fines del ICBF es dirigir y entregar en adopción a los titulares de derechos vulnerados con el fin de buscar una familia a través de la declaratoria de adopción, que se abre luego de que el Bienestar Familiar tiene conocimiento de la vulneración que sufre un menor de edad, cuando un niño o adolescente se queda sin familia, es abandonado por esta o ha sido objeto de maltrato o alguna clase de violencia, se abre entonces el proceso de restablecimiento de derechos a través del ICBF como la única institución encargada de restablecer derechos de los menores y brindarles una estabilidad familiar a través de la adopción.

Referente a lo anterior, hace falta un proceso de sensibilización a la población colombiana del compromiso social, responsable y justo en los procesos de adopción, especialmente de los adolescentes para restablecer de forma real y verdadera los derechos de los menores.

En el marco de análisis se evidencia una baja participación social de los ciudadanos frente a proyectos o planes que contribuyen a mejorar el camino de reestructurar y proteger los derechos de los menores en Colombia. Es notable, pues, la indiferencia frente a los procesos que se promueven para proteger al menor. 
Pero aun mayor es la preocupación del Estado por la evasión de la responsabilidad de padres y madres frente a la obligación con sus hijos de brindarles una estabilidad familiar, social, psicológica e incluso económica.

Son muy pocas las oportunidades de los adolescentes frente a una adopción en comparación con niños menores de siete años, las personas dispuestas a iniciar un proceso de adopción desean poder vivir y compartir con el menor adoptado todas las etapas de la vida de aquel, pero se ha dejado atrás la razón de ser, el propósito de la adopción, el cual es proteger y restablecer a todos los niños, niñas y adolescentes de Colombia, sus derechos fragmentados, es decir, el proceso de adopción se convierte en una medida de protección y garantía al menor adoptado, en donde se le da la seguridad de que todos sus derechos serán protegidos.

La política pública estatal y de inclusión social de los adolescentes vulnerados en sus derechos bajo la custodia del ICBF no responde a las necesidades y realidades concretas de jóvenes que están en lista del proceso de adaptabilidad porque este proceso en los adolescentes es baja o nula en los últimos años y uno de los factores predominantes es la edad; por ende, el ICBF asume el cuidado de estos menores en hogares sustitutos y la formación académica, técnica y profesional de aquellos que desean realizar el proyecto de vida incluso después de la mayoría de edad, pero una vez terminado los estudios superiores se desvinculan de la institución estatal.

Los resultados obtenidos a través de las encuestas a los diferentes hogares sustitutos del municipio de Villavicencio y las respuestas de la Policía de Infancia y Adolescencia muestran una gran problemática a los derechos primordiales de los menores de edad.

Se demanda un mayor seguimiento a la problemática personal social y psicológica de los niños, niñas y adolescentes bajo la custodia del ICBF a través de los hogares sustitutos.

Los lineamientos de acción para mitigar la victimización de los niños, niñas y adolescentes es clave para emprender y ejecutar alianzas de amor y seguridad al menor, pero no es suficiente el componente de prevención.

Se debe evitar a toda costa la vulneración de los derechos de los adolescentes, tener un manejo y capacitación especial con ellos, ya que según la información obtenida 
por la Policía de Infancia y Adolescencia en los últimos años son los más propensos a ser parte de bandas delincuenciales, consumo o expendio de drogas, entre otros.

Se presenta una problemática social y estatal con los adolescentes que no son adoptados y no desean seguir con sus estudios, bien sea técnicos, tecnólogos o profesionales, ya que estos adolescentes al cumplir la mayoría de edad egresan del programa estatal del ICBF y empiezan entonces a formar parte de grupos delincuenciales, ya que no tienen otra opción.

Así que el seguimiento posterior por parte del Estado a los adolescentes egresados del programa manejado por el ICBF resulta insuficiente. Por ende, se deben reestructurar los programas de prevención y recuperación social de aquellos adolescentes que necesitan de terapias psicológicas, psiquiátricas o médicas para su reinserción apta a la sociedad.

\section{REFERENCIAS}

Almonte, C., y Montt, M. (2012). Psicopatología infantil y de la adolescencia. Santiago de Chile: Mediterráneo.

Arango, R. (2005). El concepto de derechos sociales fundamentales. Bogotá: Legis.

Arenas Monsalve, G. (2011). El derecho colombiano de la seguridad social. Bogotá: Legis.

Asamblea Nacional Constituyente. (1991). Constitución Política de Colombia. Santa Fe de Bogotá: Gaceta.

Camargo, E. (2016). Positivismo, derecho y justicia en la Constitución colombiana de 1991. Revista Republicana. Núm. 21, julio-diciembre de 2016, pp. 137-158. Documento extraído el 1 de octubre de 2017 de http://ojs.urepublicana.edu.co/index.php/ revistarepublicana/article/view/333/302

Cecilia de la Fuente Lleras, D. D. (Noviembre de 2010). Lineamiento técnico para las modalidades de vulnerabilidad o adopción. Obtenido de Instituto Colombiano de Bienestar Familiar: http://www.ICBF.gov.co/portal/page/portal/Descargas1/12ModalidadesdeVul nerabilidadyAdoptabilidadRes5930.PDF 
Colombia, C. P. (1991). Constitución Politica de Colombia. Santa Fé de Bogota: La Gaceta.

Constitucion Política de Colombia. (1991). Artículo primero: Colombia Estado social de derecho. Santa Fe de Bogotá: Diario Oficial.

Cortez, S. (2016). Derechos humanos en las políticas de paz y posconflicto en Colombia. Revista Via Inveniendi et Iudidandi. Vol. 11, N. ${ }^{\circ}$, enero-junio 2016, pp. 129-145. Documento extraído el 7 de marzo de 2017 de http://revistas.usantotomas.edu.co/index. php/viei/article/view/2926/2798

De la Cueva, M. (1949). Derecho mexicano del trabajo. México: Porrúa.

De la Cueva, M. (1984). El nuevo derecho mexicano del trabajo. México: Porrúa.

Instituto Colombiano de Bienestar Familiar. (s.f.). ICBF Colombia. Recuperado el 5 de abril de 2017, de Bienestar Familiar: http://www.ICBF.gov.co/portal/page/portal/PortalICBF/ Especiales/prueba/Bienestar/Adopciones-back/InstitucionesColombia

Instituto Colombiano de Bienestar Familiar. (2014). Bienestar Familiar. Retrieved 2015 1504 from http://www.ICBF.gov.co/portal/page/portal/PortalICBF/EiInstituto

LA FM. (2015 13-03). Noticiero de la FM. Retrieved 2015 15-04 from http://www.lafm. com.co/noticias/especial-los-hijos-del-estado-179027

López, A. (2006). Elementos de derecho del trabajo. Bogotá: Ediciones del Profesional Ltda.

Lopez, D. (2013). El derecho de los jueces. Bogotá: Legis.

López Fajardo, A. (2006). Elementos de derecho del trabajo. Bogotá: Librería Ediciones del Profesional Ltda.

Morales, S. (2017). Eficacia y realidad del observatorio de familia en Colombia en Revista IUSTA, N.o 47, Julio-diciembre 2017, pp. 87-117. Documento extraído el 3 de marzo de 2017 de http://revistas.usta.edu.co/index.php/iusta/article/view/3812/3751

Páez, P. y otros. (2017). Necesidades humanas y política social. Revista Republicana. Núm. 22, enero-junio de 2017, pp. 131-158. Documento extraído el 3 de octubre de 2017 de http://ojs.urepublicana.edu.co/index.php/revistarepublicana/article/view/380/333

Papalia, D., Wendkos, S., y Duskin, R. (2009). Psicología del desarrollo. México: McGraw Hill. 
Parejo, L. (2016). Sobre el binomio libertad y seguridad en el derecho. Revista IUSTA, N. ${ }^{\circ} 45$, julio-diciembre de 2016, pp. 107-128. Documento extraído el 5 de abril de 2017 de http://revistas.usta.edu.co/index.php/iusta/article/view/3293/3103

Pla, A. (1975). Los principios del derecho laboral. Buenos Aires: Depalma.

Presidencia de la República de Colombia. (2014). Decreto 1047. Bogotá: Diario Oficial.

Proceso gestión para la protección lineamiento técnico de modalidades para la atención de niños, N.Y. (2 de marzo de 2017). Obtenido de http://www.ICBF.gov.co/portal/page/ portal/PortalICBF/procesos/misionales/proteccion/restablecimiento-derechos/3C15FE A84482232CE053528511ACF6B5

Saidiza, H. y Carvajal, J. (2016). Un análisis de la legislación penal de emergencia inscrita en el manejo jurídico de la protesta social. Revista Verba Iuris. No. 35, enero-junio 2016, pp. 13-39. Documento extraído el 5 de mayo de 2017 de http://www.unilibre.edu.co/ verbaiuris/2-noticias/noticias/567-nuevas-logicas-autoritarias-y-crisis-del-estado-dederecho-en-colombia-un-analisis-de-la-legislacion-penal-de-emergencia-inscrita-en-elmanejo-juridico-de-la-protesta-social

Semana. (2013 06-07). Revista Semana. Retrieved 2015 12-04 from http://www.semana. $\mathrm{com} /$ nacion/articulo/ninos-esperanzas-adoptados/349850-3

Vanegas, A. (2011). Derecho individual del trabajo. Bogotá: Librería Ediciones del Profesional Ltda. 